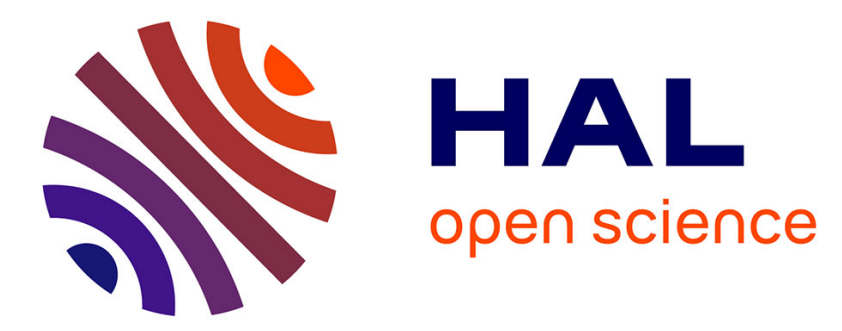

\title{
Sensitivity to morpheme units in English as L2 word recognition
}

\author{
Séverine Casalis, Eva Commissaire, Lynne G. Duncan
}

\section{To cite this version:}

Séverine Casalis, Eva Commissaire, Lynne G. Duncan. Sensitivity to morpheme units in English as L2 word recognition. Writing Systems Research, 2014, Reading Morphologically Complex Words in a Second Language, 7 (2), pp.186-201. 10.1080/17586801.2014.976165 . hal-02539910

\section{HAL Id: hal-02539910 https://hal.univ-lille.fr/hal-02539910}

Submitted on 25 Mar 2021

HAL is a multi-disciplinary open access archive for the deposit and dissemination of scientific research documents, whether they are published or not. The documents may come from teaching and research institutions in France or abroad, or from public or private research centers.
L'archive ouverte pluridisciplinaire HAL, est destinée au dépôt et à la diffusion de documents scientifiques de niveau recherche, publiés ou non, émanant des établissements d'enseignement et de recherche français ou étrangers, des laboratoires publics ou privés. 
How to cite :

Casalis, S., Commissaire, E., \& Duncan, L. G. (2015). Sensitivity to morpheme units in English as L2 word recognition. Writing Systems Research, 7(2), 186-201.

ISO 690

Sensitivity to morpheme units in English as L2 word recognition

Running head: sensitivity to morphemes in L2 word recognition

Séverine Casalis, Eva Commissaire, Lynne G. Duncan, 
Corresponding Author

Severine Casalis

Université Lille Nord de France, Laboratoire URECA (EA 1059).

Rue du barreau, 59653 Villeneuve d'Ascq, France.

Email: severine.casalis@univ-lille3.fr

Tel: 0033 (0) 320406369.

Co- authors

Lynne G. Duncan. University of Dundee, School of Psychology. Nethergate, DD1 4HN

Dundee, Scotland, United Kingdom.

Email: 1.g.duncan@dundee.ac.uk

Eva Commissaire. Université de Strasbourg. Laboratoire de Psychologie des Cognitions (EA 4440). 12 rue Goethe 67000 Strasbourg, France.

Email: commissaire@unistra.fr 


\begin{abstract}
Little is yet known about how L2 learners process morphology during visual word recognition. Two points of view may be contrasted: the first one suggests that L2 learners, as less proficient speakers, may be less sensitive to the computational aspects of word processing such as the morphological structure of complex words, relying more on lexical information; whereas, the second one suggests that word processing is constrained mainly by linguistic aspects, making L2 learners as sensitive to word structure as native speakers. While previous studies have mainly focused on proficient to highly proficient L2 speakers, the present study compared L2 learners of low proficiency with those of intermediate to high levels of proficiency. The role of morphological structure in word recognition and pseudoword processing was examined by manipulating the presence of embedded words and suffixes in items presented for L2 lexical decision. Contrasting patterns in L2 word recognition were observed between groups as the low proficiency group was more sensitive to the presence of an embedded word than the higher proficiency group in both accuracy and speed. However, pseudowords made up of an embedded word and suffix were significantly more likely to be wrongly accepted as words than other pseudowords by both groups. Furthermore, correct rejection of these items as words induced longer latencies in both groups, indicating a morphological analysis of these pseudowords. Together, the results show that L2 learners, including those who are low in proficiency, are sensitive to the morphological structure of written L2 words.
\end{abstract}




\section{Sensitivity to morpheme units in English as L2 word recognition}

The view that visual word recognition involves a morphological decomposition process was first proposed by Taft (Taft \& Forster, 1975, and more recently, Taft, 1994). Taft suggested that word recognition involves mandatory affix stripping. This obligatory decomposition is blind to meaning and is accommodated theoretically by a morpheme level within localist models (Taft \& Forster, 1975) or by the overlap between phonological, orthographic and semantic codes in connectionist models (Seidenberg \& Gonnerman, 2000). Other theoretical proposals (Schreuder \& Baayen, 1995) consider that morphological decomposition is optional, based on the relative frequencies of bases and whole words with low frequency words being most prone to be decomposed in lexical access, particularly when they include high frequency bases (Baayen, Dijkstra \& Schreuder, 1997; Bertram, Baayen \& Schreuder, 2000). This account therefore postulates two mechanisms in morphologically complex word recognition, either storage (i.e., whole-word form) or computation (i.e., parsing). A contrasting view is that morphological decomposition is driven instead by higher-level processing and depends primarily on semantic knowledge (Marslen-Wilson, Tyler, Waksler, \& Older, 1994). According to this view, decomposition would be more likely if an affix makes a strong rather than a weak contribution to the meaning of a word.

Two processes have been distinguished in monolingual studies: (1) a morphoorthographic process, which is sensitive to morpheme-like units and is blind to meaning, revealed via masked priming effects for morphologically opaque pairs such as $<$ corner $>$ $<$ CORN $>$ (Rastle, Davis, Marslen-Wilson \& Tyler, 2000; Rastle, Davis \& New, 2004); and (2) a morpho-semantic process, which is sensitive to genuine morphological relatedness, revealed through cross-modal and long-term priming (Feldman, O’Connor \& Moscoso del Prado Martin, 2009). Additionally, the greater priming effects observed when morphological prime-target pairs are semantically related (e.g., $<$ viewer $>$ - $<$ VIEW $>$ ) as compared to semantically unrelated also called morphologically opaque (e.g., $<$ corner $>-<\mathrm{CORN}>$ ), suggest that the morpho-semantic process also operates in a top-down manner (e.g. Diependaele, Sandra \& Grainger, 2005, but see Rastle et al, 2004 for an opposing view).

Thus, the evidence strongly suggests that the properties of component morphemes in derivations are processed by native speakers during visual word recognition especially as priming studies also reveal both significant base (e.g., $<$ darkly $>-<$ DARKNESS $>$, Rastle et al, 2000) and suffix effects (e.g., $<$ darkness $>-<$ HAPPINESS $>$, Duñabeitia, Perea \& Carreiras, 
2008). Moreover, morphological effects have been observed in pseudoword processing, where both interpretable derived pseudowords (e.g. <quickify>) and non interpretable derived pseudowords (e.g. $<$ sportation $>$ ) facilitated recognition of the pseudo-base, respectively $<$ quick $>$ and $<$ sport> (Longtin \& Meunier, 2005; see also Kim, Wang \& Ko, 2011 in a crosslanguage priming study).

The present study focuses on the question of morphological processing in written word recognition but in a second language (L2) rather than in native language (L1). A contrasting theoretical position has been proposed for L2 learning, namely that L2 speakers rely on whole word retrieval in visual word recognition due to a lack of sensitivity to computational aspects of the L2. This proposal that L1 and L2 processing may differ markedly is based on work by Ullman (2004) which emphasised the distinction between declarative and procedural processing in L2. Language processing is thought to involve a lexical store of memorized words that depends on declarative memory and a mental grammar that includes combinatorial rules. Each process in located in a separate brain region: the medial temporal and prefrontal cortical regions for the former, and the frontal/basal-ganglia circuits for the latter. According to Ullman (2005), L2 learning and processing are largely dependent on the lexical memory system and computations are used less in L2 than in L1. Based on this assumption, Silva and Clahsen (2008) hypothesised that L2 late learners would be less sensitive than L1 native speakers to the morphological structure of the words since they mostly rely on lexical retrieval processes.

To date, only a few studies have examined this issue in relation to derivational morphology, although it has been more extensively examined for inflectional morphology (e.g., Feldman, Kostic, Basnight-Brown, Filipovic-Durdevic \& Pastizzo, 2009; Gor \& Jackson, 2013). As our study is concerned with derivational morphology, we will consider only those studies that include derivations. Most investigations of L2 speakers have used a priming paradigm previously conducted with native speakers, with the L2 prime being a derived form and the L2 target, a lexical base form. Silva and Clahsen (2008) compared native English speakers with late learners of English who had Chinese, German or Japanese as a native language. No L2 priming effects emerged for inflections, however, lexical decision tasks conducted with highly productive derived forms (the suffixes $<$ ness $>$ and $<$ ity $>$ ) yielded results showing morphological priming effects (e.g., $<$ bitterness $>-<$ BITTER $>$ ) in all three L2 groups. However, while the native speakers displayed equivalent priming for identity (e.g. $<$ bitter $>$ - $<$ BITTER $>$ ) and morphological (e.g. $<$ bitterness $>$ - $<$ BITTER $>$ ) conditions, the L2 groups all showed greater identity priming, leading the authors to conclude that L2 speakers 
are less sensitive than L1 speakers to the morphological structure of words. Clahsen, Felser, Sato and Silva (2010) similarly concluded that advanced adult L2 learners were less sensitive to morphological structure, especially for inflectional morphology.

A different conclusion however has been drawn by Diependaele, Duñabeitia, Morris and Keuleers (2011) from lexical decision experiments using three categories of masked primes: (1) transparent derived primes (e.g., <viewer $>-<$ VIEW $>$ ); (2) opaque or pseudosuffixed primes (e.g., $<$ corner $>-<\mathrm{CORN}>$ ); and (3) form control primes (e.g., $<$ freeze $>-$ $<$ FREE $>$ ). Experiment 1 replicated previous investigations of morphological processing in L1 native English speakers, finding significant morphological priming and a larger priming effect in the transparent condition compared to the opaque and form conditions (see Feldman, O’Connor and Moscoso del Prado Martín, 2009). However, there was no difference between form and opaque conditions, contrary to previous work (Rastle et al, 2000, 2004; Longtin, Segui \& Hallé, 2003). Experiments 2 and 3 were conducted with Spanish and Dutch speakers, respectively, to ensure generalisation to different L2 learner groups. The Spanish speakers were considered as the more highly proficient in English (L2), even though the level of L2 proficiency of the Dutch group was not low. The Spanish group had started learning English at around 8 years old and regularly attended final-level courses of English as a second language, experiencing approximately 12 hours of exposure to English per week. In contrast, the Dutch group started learning English at about 12 years of age and was exposed to the English language on average for 7 hours per week. Thus, the groups differed both in age of acquisition and first language. Measures of proficiency led to mixed results. The Spanish group had higher comprehension and reading skills than the Dutch group, consistent with their greater L2 exposure. For all these reasons, the Spanish group was considered as more proficient than the Dutch group. However, no difference was found between the groups in speaking skills either in terms of overall comfort or overall proficiency. This finding suggests that the proficiency level of the Dutch group was also rather high. When considering the entire sample of participants, similar morphological priming effects were found between L2 and L1 speakers, with the largest priming effect obtained in the transparent condition, intermediate priming in the opaque condition, and the smallest effect in the form condition. The interaction between group and priming effect revealed that the pattern of morphological processing by L1 and L2 speakers was identical except for the faster response times of the L1 group (see also Otto, 2012). Overall, the two L2 learner groups performed very similarly, despite the differences in age of acquisition, first language and L2 skills such as reading and comprehension, suggesting that L2 speakers process morphological information much as 
native speakers do. Using a different paradigm, namely morphological awareness tasks such as relational awareness, syntactical awareness and distributional awareness, Koda, Takahashi, and Fender (1998) demonstrated the impact of L1, here Korean vs Chinese, in sensitivity to L2 morphological structure. In addition, the authors documented a connection between proficiency and sensitivity to distributional properties.

Thus, contradictory results have emerged regarding the strength of morphological priming in L2. Silva and Clahsen (2008) noted a greater sensitivity to word frequency in L2 lexical decision, which is consistent with their attribution of the weaker L2 morphological effects to a reliance on whole-word processing. However, Diependaele et al (2011) highlighted other factors that they felt might explain the discrepancy with their results. In particular, they pointed to the small number of items per condition (6 to 7) and the use of only two suffixes, but other factors included the participants' level of L2 exposure and proficiency. Diependaele et al (2011) predict that weaker morphological processing in L2 may simply be a transitional phase before fully proficient functioning is achieved. An alternative view is that familiarity with the sublexical characteristics of the orthography occurs with exposure to written language, as demonstrated by Merkx, Rastle and Davis' (2011) study of novel affix learning. In this case, morphological processing would be present from the earliest phases of acquisition and the developmental course of this skill would be highly dependent on the properties of the language being acquired.

Indeed, we suggest that this debate may be complicated by the presence of confounds between a number of factors, namely, L2 age of acquisition, L1 features and level of L2 proficiency. Silva and Clahsen (2008) argued that late learning (age of acquisition) leads to a lower sensitivity to morphology and a greater reliance on whole-word processing. The testing of such a hypothesis would involve comparison of L2 groups matched on L1 while differing in age of acquisition, which is obviously difficult to perform. In addition, the contribution of proficiency remains to be investigated. Although L2 proficiency was considered to be high in the previous work by both Silva \& Clahsen (2008) and Diependaele et al (2011), age of acquisition was somewhat older in the Silva and Clahsen than in the Diependaele et al study (14 years vs. 8-12 years, respectively). This may have been all the more critical in Silva and Clahsen's study since the nature of the L1 (i.e. Japanese, Chinese) and L2 (i.e. English) oral languages differed markedly. It seems relevant to begin to examine the hypothesis of a reliance on morphological processing vs. whole-word processing in experiments that control more closely for the influence of L2 age of acquisition, L2 proficiency and the nature of the L1. 
Our focus will be on level of proficiency since Diependaele et al (2011) argue explicitly that the "potential disparities [among results] might depend on the linguistic proficiency level of non-native speakers of a language" (p. 346). These authors envisage a developmental trajectory of increasing sensitivity to morphological units in L2 visual word recognition as proficiency improves. A parallel may exist with L1 acquisition, as discussed by Rastle and Davis (2008), where the growth of orthographic knowledge leads to the use of cues such as bigram frequency or high-probability orthographic sequences in developing sensitivity to morphemes. As L2 exposure and proficiency increase, mounting sensitivity to such sublexical cues might lead to morphemes being engaged prior to lexical access for complex words, or being activated alongside whole-word representations. One early indicator of sublexical processing may be the use of high frequency embedded words, which low proficiency L1 and L2 readers may use to help them process lower frequency morphologically complex words (Lemhöfer, Koester \& Schreuder, 2011).

The present study aims to explore the issue of morphological processing by focusing on the impact of proficiency in L2 learners. Two groups matched on age of acquisition and first language (French) but differing in English as L2 proficiency will be compared. On this basis, we test two contrastive hypotheses. A first one, based on previous predictions from Ullman's (2004) work is that the group of low proficiency L2 learners may process whole word forms and would be much less likely to be engaging with the componential aspects of L2 visual word recognition. According to an alternative view, both groups of participants have had sufficient length of exposure to the L2 to exhibit preliminary familiarity with the sublexical characteristics of the orthography (e.g. Merkx, Rastle \& Davis, 2011; Rastle \& Davis, 2008). Here morphological processing depends more strongly on language properties with even low proficiency L2 learners exhibiting sensitivity to morphological structure and showing similar patterns to more proficient L2 learners. Diependaele et al (2011) suggested a hybrid position that differences in morphological processing may "reflect an intermediate state in the transition towards the target (L1) architecture rather than a fundamentally different way of handling native and non-native language input" (p. 356). Thus, the low proficiency L2 learners could be less sensitive to morphological units than their more proficient counterparts. To our knowledge, no previous study has compared morphological processing among L2 learners of varying proficiency, with a focus on low proficiency and including a match for the L1 and the L2 age of acquisition.

A simple lexical decision task was selected for the present study based on our previous work (Duncan, Gray, Quémart \& Casalis, 2010; Quémart, Casalis \& Duncan, 2012), which 
yielded evidence of emerging sensitivity to derivational morphology among young monolingual readers. The presence of base-like embedded words and derivational suffix endings was manipulated orthogonally within the task to allow examination of the relative contribution of these morphemes to the L2 word recognition process. Interestingly, this task uncovered some differences between English and French language processing, although the results obtained in each study using similar materials have not yet been directly compared.

In the United Kingdom study, with third and fourth grade native English-speakers (Duncan et al, 2010), the contribution of morphemes to lexical decisions was narrow being largely limited to accuracy. For words, the presence of an embedded word had little effect but, in the absence of an embedded word, the presence of a suffix improved accuracy. In the French study, both bases and suffixes facilitated word reading accuracy and speed across third and fifth grade native French-speakers (Quémart et al, 2012). In both languages, embedded words and suffixes reduced accuracy for pseudowords, leading to a higher error rate in rejecting the seemingly more word-like items that contained both an embedded word and a suffix (e.g. gifter). Overall, it appears that there was an emerging influence of morphemes in word recognition among these young readers, although this was more evident among the French- than English-speakers. For pseudowords, the combination of an embedded word plus a suffix interfered with the correct classification of such items in both language groups. Thus, these results suggest that this simple lexical decision task has the potential to show sensitivity to morphological structure in word recognition and morphological processing in reading novel pseudowords even among unskilled participants, namely, young readers in these studies. It should also be emphasised that some aspects of the task vary depending on the language under investigation, while other aspects are constant across languages. More specifically, while the English-speaking participants displayed a narrower sensitivity to morphemic units in word recognition than the French participants, a strong impact of morphemic units was found in pseudoword processing in both languages.

In the present study, we used this simple lexical decision task in order to examine the controversial issue of morphological processing in L2 (cf. Silva \& Clahsen, 2008 vs. Diependaele et al, 2011). While many aspects of the L2 learning context may influence this issue, we decided to focus on proficiency by contrasting a group of low proficiency L2 learners with a more proficient group of L2 learners. In order to control for other influential factors (L1, L2 age of acquisition), the two proficiency groups of L2 learners were matched on both first language (French) and L2 age of acquisition. If L2 learners depend on a lexicalised process in reading then our expectation would be that our L2 learner groups would 
be insensitive to morphology in the lexical decision task. However, it appears likely from previous work by Diependaele et al (2011) that the use of morphology may depend on proficiency levels, in which case we expect group differences in sensitivity to morphemes both in word recognition and novel word processing. Alternatively, if sensitivity to morphological structure depends on basic language properties as well as participant characteristics, we should not expect group differences in sensitivity to morpheme units in L2 word and pseudoword processing, although the more proficient group may respond more quickly and more accurately in the task.

\section{Method}

\section{Participants}

Forty-one native speakers of French from the Universities of Lille and Strasbourg in France participated in the study. None of them were early bilingual. Their ages ranged from 21 to 32 , with a mean age of 25 . Two groups of participants were recruited for the study. The first, the "low proficiency" group studied English at school, have never spent more than one week abroad in an English-language country and have had no opportunity for additional training in English. The second, the "higher proficiency" group also learned English at school; however, they had all spent at least three months abroad between the ages of 16 to 21 in an English speaking country (United Kingdom, Canada, US, Australia). There were 13 females and 9 males in the less proficient group and 12 females and 7 males in the more proficient group. Each participant reported having normal or corrected-to-normal vision. All had studied English at secondary school for 7 years where English exposure was about 3 to 4 hours per week. Age of acquisition in both groups was 8, as English started at Grade 3 with about 1 to 2 hours of English exposure. The less proficient students reported a low to intermediate level of English, corresponding roughly to the B1 level according to the Reference Framework (Council of Europe E.C., 2001) while students from the higher proficiency group reported an intermediate to advanced level of English, corresponding roughly to the B2 or C1 level. Proficiency was then also assessed by means of a word translation test from L1 to L2 with three levels of difficulty according to item frequency. The mean English item frequencies from the CPWD database (Masterson, Stuart, Dixon, \& Lovejoy, 2003) for the three levels are: "beginners" Mean = $522(\mathrm{SD}=743)$; "intermediate" Mean = $72(\mathrm{SD}=96)$; and "advanced" Mean = $24(\mathrm{SD}=36)$. The mean French item frequencies (from the Lexique 
database, New Pallier, Ferrand \& Matos, 2001) for the three levels are: "beginners" Mean = $215(\mathrm{SD}=211)$; "intermediate" Mean = $31(\mathrm{SD}=22)$; and "advanced" Mean = $4(\mathrm{SD}=6)$. Mean percentage accuracy on the translation test for the "beginners", "intermediate" and “advanced" levels in both groups are reported Table 1. In sum, participants can be considered as rather "low proficiency" L2 speakers in the less proficient group and "intermediate to high proficiency" in the more proficient group.

insert Table 1 about here

\section{Materials}

Four sets of 20 words and 20 matched pseudowords were constructed (see Appendix). There were four conditions of words resulting from the combination of presence or absence of an embedded word (W) and a suffix (S) : (i) W+S+ (embedded word and suffix, e.g. $<$ cloudy>); (ii) W+S- (embedded word but no suffix, e.g. < needle>); (iii) W-S+ (no embedded word but a suffix, e.g. <pretty>); and (iv) W-S- (no embedded word and no suffix, e.g. $<$ turtle $>$ ). Note that the words in the $\mathrm{W}+\mathrm{S}+$ condition (i) were derived words and that this was the only condition where letter strings correspond to genuine morphemes; in other conditions, they were "morpheme-like" units. Pseudowords were constructed according to the same principle: (i) $\mathrm{W}+\mathrm{S}+$ (e.g. < proudy $>$ ); (ii) $\mathrm{W}+\mathrm{S}-($ e.g. $<$ foodle $>$ ); (iii) $\mathrm{W}-\mathrm{S}+$ (e.g. $<$ slinny $>$ ); and (iv) W-S- (e.g. $<$ birtle $>$ ). Pseudowords in the $\mathrm{W}+\mathrm{S}+$ condition (i) contained two morpheme-like units.

We selected high frequency words and suffixes typical of the vocabulary of Englishspeaking children using the CPWD lexical database (Masterson, Stuart, Dixon \& Lovejoy, 2003). Moreover, suffixes were chosen to maximize the likelihood that they would be known by the L2 learners. A pre-test was also conducted among a group of French students to ensure they knew the words. The words were matched to pseudowords with a similar structure. The word conditions were matched on whole word frequency using CPWD, $F<1$ (see Table 2). Embedded word frequency was matched for real words in the $\mathrm{W}+\mathrm{S}+$ and $\mathrm{W}+\mathrm{S}-$ conditions $($ Mean $=254, \mathrm{SD}=434$ and Mean $=474, \mathrm{SD}=1128$, respectively, $p=.42)$ and for pseudowords $($ Mean $=203, \mathrm{SD}=308$ and Mean $=382, \mathrm{SD}=735$ for $\mathrm{W}+\mathrm{S}+$ and $\mathrm{W}+\mathrm{S}-$, respectively, $p=.32$ ). Words and pseudowords were also matched on number of letters and phonemes (Mean number of letters $=6, \mathrm{SD}=0.8$; Mean number of phonemes $=4.8, \mathrm{SD}=$ 0.76 ) and all four conditions for both words and pseudowords were matched on these two criteria (all $p s>.20)$. 
In addition we ensured that there were no English-French cognate words, either identical or neighbour cognates. Further, the familiarity of the embedded word was systematically assessed after participants had completed the lexical decision task. Familiarity of the embedded word within the $\mathrm{W}+\mathrm{S}+$ and $\mathrm{W}+\mathrm{S}$ - conditions was matched, even after removing items which were not known by participants $(p>.35)$.

\section{Insert Table 2about here}

\section{Procedure}

The experiment was controlled by E-Prime software (Version 2, Schneider, Eschmann \& Zuccolotto, 2002) running on a Dell Latitude E5430 laptop. Participants were instructed to focus on the middle of the screen. A trial started with the presentation of a white cross at the centre of a black screen for 1,000 ms, followed by a white, lower-case target in Courier New font (point 25). Targets remained visible until the participant's response or, if there was no response, for a maximum duration of 5,000 ms. Reaction times (RTs) were recorded using a two-button response box. Instructions were standard for the lexical decision task (i.e. push the "yes" button if it is an English word, and the "no" button if not), with the addition of an instruction similar to those of the go/no go task (i.e push the "yes" button as soon as you recognize a word). We decided to include this instruction because our low proficiency participants may be conscious of having a restricted vocabulary and may lack confidence in responding in the lexical decision task. Participants were also informed that words were common words and that there were no rare words. The choice of buttons for word and nonword responses depended on dominant hand, participants having to respond "yes" with their dominant hand. Finally, participants were instructed to respond as quickly and accurately as possible. L2 targets were presented in a different random order for each participant. The experiment started with twelve practice trials and lasted around 10 minutes.

\section{Data treatment and analysis}

Three words with error percentages greater than the chance level of 50\% and 6 items (5 words and 1 pseudoword) that were wrong categorised were excluded from the analysis (see items marked with asterisk in the appendix). The new sets of stimuli were still matched for length and frequency. RTs slower than $2.5 \mathrm{SD}$ ms $(1.4 \%$ of the word data and $1.2 \%$ of the pseudoword data) were also excluded. To test the influence of embedded words and suffixes on lexical decisions, we conducted a $2(\mathrm{~W}+, \mathrm{W}-)$ x $2(\mathrm{~S}+, \mathrm{S}-)$ analysis of variance within a 
repeated measures design. Analyses were conducted with participants $\left(F_{1}\right)$ and items $\left(F_{2}\right)$ as random variables. Results are presented Table 3.

\section{Results}

\section{Words}

Accuracy. There was a main effect of group, $F_{l}(1,41)=39.46, p<.001, \eta_{\mathrm{p}}{ }^{2}=.50$, $F_{2}(1,68)=46.00, p<.001, \eta_{\mathrm{p}}^{2}=.40$, the higher proficiency group being more accurate than the lower proficiency group (respectively, $91.56 \%$ and $75.49 \%$ of correct responses). There was no main effect of embedded word, $F_{l}(1,39)=1.78, p=.19, F_{2}<1$. However, there was a group by embedded word interaction, $F_{l}(1,39)=8.45, p=.006, \eta_{\mathrm{p}}{ }^{2}=.18, F_{2}(1,68)=4.01, p$ $=.049, \eta_{\mathrm{p}}^{2}=.06$. Planned comparisons revealed a significant effect of embedded word in the less proficient group, $t(21)=2.92, p<.001$, although it was not significant in the more proficient group, $t(18)=1.03, p=.32$. There was a main effect of suffix, $F_{l}(1,39)=5.41, p=$ $.03, \eta_{\mathrm{p}}{ }^{2}=.122$, but $F_{2}<1$. Words with a suffix were recognised more accurately than words without a suffix (respectively, $84.19 \%$ and $81.68 \%$ ). The group by suffix interaction marginally failed to reach significance by participants but was not significant by items, $F_{l}(1$, $39)=3.80, p=.06, F_{2}<1$. The base by suffix interaction was significant by participants and marginal by items, $F_{l}(1,39)=9.29, p=.004, \eta_{\mathrm{p}}{ }^{2}=.19, F_{2}(1,68)=3.81, p=.055, \eta_{\mathrm{p}}{ }^{2}=.06$. The presence of a suffix had a stronger, although marginal, impact when there was no embedded word (respectively, with and without a suffix, 85.04\% and 78.90\%,t(40) $=1.94, p$ $=.06$ ) than when there was an embedded word (respectively, with and without a suffix, $84.47 \%$ and $83.33 \%, t(40)=0.75, p=.46)$.

Response latencies. Response latencies did not differ across groups, $F_{S}<1$. There was a main effect of embedded word by participants which was marginal by items, $F_{l}(1,39)=$ $5.15, p=.03, \eta_{\mathrm{p}}^{2}=.12, F_{2}(1,68)=3.71, p=.065, \eta_{\mathrm{p}}^{2}=.051$. Words including an embedded word were recognized faster than other words (718 ms and $732 \mathrm{~ms}$, respectively). There was a group by embedded word interaction by participants only, $F_{l}(1,39)=5.25, p=.03, \eta_{\mathrm{p}}{ }^{2}=.12$, $F_{2}(1,68)=3.14, p=.08, \eta_{\mathrm{p}}{ }^{2}=.04$. Planned comparisons revealed a significant effect of embedded word in the less proficient group, $t(21)=3.30, p<.001$, while it was not significant in the more proficient group, $t(18)=0.01, p=.99$. No other effect was significant.

\section{Pseudowords}


Accuracy. There was an effect of group, $F_{1}(1,39)=10.11, p=.003, \eta_{\mathrm{p}}{ }^{2}=.21, F_{2}(1$, $68)=78.46, p<.001, \eta_{\mathrm{p}}{ }^{2}=.51$, which reflected higher accuracy for the more proficient group as compared to the less proficient group (respectively $94.02 \%$ and $84.07 \%$ of correct responses). The main effects of embedded word, $F_{1}(1,39)=92.27, p<.001, \eta_{\mathrm{p}}^{2}=.71, F_{2}(1$, $75)=36.80, p<.001, \eta_{\mathrm{p}}{ }^{2}=.33$, and suffix, $F_{l}(1,39)=5.84, p=.02, \eta_{\mathrm{p}}{ }^{2}=.13$, but $F_{2}(1,75)=$ $1.20, p=.28, \eta_{\mathrm{p}}{ }^{2}=.02$, were significant, with the presence of each unit leading to a higher error rate in pseudoword classification (for embedded words: $76.65 \%$ vs. $92.65 \%$; for suffix: $83.26 \%$ vs. $86.04 \%$ ). There was no interaction between either of these units and group, all $F_{\mathbf{S}}<1$, suggesting that the presence of a unit had a comparable impact across groups. The interaction between embedded word and suffix was significant, $F_{l}(1,39)=18.68, p<.001$, $\eta_{\mathrm{p}}{ }^{2}=.32, F_{2}(1,75)=4.22, p=.04, \eta_{\mathrm{p}}^{2}=.05$. Planned comparisons revealed that accuracy was lower in rejecting pseudowords containing an embedded word if there was also a suffix present $(72.56 \%$ vs. $80.79 \%$ of correct responses for $\mathrm{W}+\mathrm{S}+$ and $\mathrm{W}+\mathrm{S}-$, respectively, $t(40)=$ $4.16, p<.001)$. In contrast, there was no impact of the suffix in the absence of an embedded word (93.97\% and $91.34 \%$ of correct responses, for W-S+ and W-S, respectively).

Response latencies. Response latencies were similar in both groups, $F_{\mathbf{S}}<1$. There was a significant effect of embedded word, $F_{l}(1,39)=60.21, p<.001, \eta_{\mathrm{p}}{ }^{2}=.61, F_{2}(1,75)=$ $17.73, p<.001, \eta_{\mathrm{p}}{ }^{2}=.19$, indicating that pseudowords containing an embedded word were rejected more slowly than those without an embedded word (891 ms vs. 824 ms, respectively). There was no interaction between group and embedded word, suggesting that the effect was comparable in both groups, $F<1$. Similarly, there was a significant effect of suffix by participants which was marginal by items, $F_{l}(1,39)=28.12, p<.001, \eta_{\mathrm{p}}^{2}=.42$, $F_{2}(1,75)=3.78, p=.056, \eta_{\mathrm{p}}{ }^{2}=.05$. This showed that pseudowords containing a suffix were rejected more slowly than those ending with a non-suffix letter string $(878 \mathrm{~ms}$ vs. $838 \mathrm{~ms}$, respectively). This effect was comparable in both groups, $F_{S}<1$. The embedded word by suffix interaction was significant, $F_{l}(1,39)=17.14, p<.001, \eta_{\mathrm{p}}{ }^{2}=.31, F_{2}(1,39)=3.92, p=$ $.048, \eta_{\mathrm{p}}{ }^{2}=.05$. Planned comparisons revealed that response latencies when an embedded word was present increased when a suffix was also present, $t(40)=2.45, p=.02$, while response latencies did not differ according to the presence of a suffix when there was no embedded word, $t(40)=0.19, p=.85$, ns.

Insert Table 3 about here. 


\section{General Discussion}

While it is acknowledged that the visual word recognition system incorporates a mechanism of morphological analysis, it is less clear whether this system is restricted to speakers with an advanced knowledge of the language or whether it generalises to L2 language learning. Previous studies have shown contradictory findings concerning masked morphological priming effects in L2 visual word recognition, making it uncertain whether reading in L2 involves morphological decomposition or whole word retrieval. All of the participants tested in the previous studies were judged to be highly proficient L2 speakers with a moderate exposure to L2 (about 8 to 10 hours per week), making it difficult to determine whether any observed morphological effects depended on an advanced knowledge of the language and/or on a sufficient written exposure to allow orthographic cues to incorporate morphemes into the word recognition system. In addition, previous studies examined L2 groups of varying levels of proficiency, age of acquisition and first language. The aim of the present study was thus to compare two groups of participants with similar L1 (i.e. French), similar L2 age of acquisition (i.e. 8 years old) but who differed in level of L2 proficiency, mainly due to the fact that the low proficiency group had never spent time in an English-speaking country while the higher proficiency group had spent at least four months in an English-speaking country.

Based on previous work conducted successfully with young children who have limited language experience due to their age (Duncan et al, 2010; Quémart et al, 2012), we decided to assess L2 sensitivity to morphemes using a lexical decision task, in which the presence of an embedded word and a suffix was systematically manipulated in both words and pseudowords. Key aspects of the simple lexical decision task are that is allows sensitivity to both base and suffix to be explored simultaneously, it is suitable for examining smaller vocabularies and it enables exploration of which aspects are taken into account when L2 speakers have to read a novel word, such as a pseudoword. The impact of proficiency, which is measured here by the degree of exposure to the language and vocabulary size, was compared using two groups of L2 learners (low vs. intermediate to high proficiency L2 learners), who were matched on L2 age of acquisition.

First, our results clearly indicate sensitivity to morphological structure in both word recognition and pseudoword processing in terms of accuracy and latency of responses. A suffix effect was observed regardless of proficiency, indicating an accuracy advantage for words with a suffix ending over those with a non-suffix ending, in spite of controls for bigram frequency and length. Importantly, however, the embedded word effect interacted with group 
revealing a significant effect only for the less proficient group, for whom the presence of an embedded word increased accuracy and speeded up the word recognition process. These results suggest that the less proficient L2 group may be more sensitive to the internal structure of words. This is interesting as it parallels findings from young readers (Carlisle \& Stone, 2005, Duncan et al, 2011), namely that suffixed words are read more accurately than nonmorphological words with a suffix-like ending (e.g. <lucky> vs. <pretty>). This outcome has been interpreted in terms of frequency: as derived words are relatively infrequent and base words tend to be higher in frequency, complex word processing may rely at least partially on base identification. This interpretation has been reinforced by the fact that children have been shown to be more accurate and to respond faster in reading derived words with high rather than low base frequencies when such words are low in surface frequency (Deacon \& Whalen, 2011). These results suggest that children are sensitive to morphological structure. Similarly our results suggest that for low proficiency L2 learners only, L2 word processing relies on embedded word identification.

Our pseudoword data indicate a slightly different pattern of results. The presence of both suffixes and embedded words reduced accuracy and increased speed of response. Moreover, the combination of an embedded word and a suffix led to even larger effects. This clearly indicates that L2 speakers do process morpheme units when they encounter novel words. Finally, in contrast to word processing, pseudoword processing was comparable in both groups of L2 learners. Thus, it appears that novel or infrequent words are processed through their morphological constituents by both low and higher proficiency groups of L2 learners.

The higher proficiency group was more accurate than the low proficiency group in both word and pseudoword processing, as might be expected. In addition, the higher proficiency group reached ceiling values in accuracy scores. Note however that the groups did not differ in response latencies. The absence of a group effect on latencies seems noteworthy as it suggests that, at least for the groups examined here, proficiency affects size of vocabulary but not speed of word recognition.

Thus in all, it appears that our results do not provide consistent support for any of the views that were outlined in the Introduction. The theories turn on the question of whether morphological processing depends on proficiency: one view that emphasizes the influence of language characteristics, suggests that morphological processing does not depend on proficiency but another view follows Ullman (2005)'s suggestion, based on age of acquisition, that L2 learners are not sensitive to computational aspects of language. 
Diependaele et al (2011) adopted a hybrid position, with a transitional phase where low proficiency L2 learners would not be sensitive to morphemic units. Our results do not confirm these views, in that the low proficiency group displayed a stronger sensitivity to morphemic units in word recognition. It could be that due to their low level of proficiency, they do not rely on whole word processing when words are long and infrequent but instead rely more on short and embedded words which are higher in frequency. Nevertheless, our results are partially compatible with the view that sensitivity to morphology is unrelated to proficiency when we consider pseudoword processing. Both the less and more proficient groups were observed to process morphemic units in novel words (pseudowords) and the extent of this morphological sensitivity was similar across groups. Thus, our results are most consistent with the view that L2 learners make similar use of morphemic units in visual word recognition regardless of their proficiency level.

As mentioned in the introduction, the design of the present experiment using the lexical decision task was adapted from our previous work with unskilled readers, namely Grades 3 to 5 English-speaking and French-speaking children (Duncan et al, 2010; Quémart et al, 2012). It is noteworthy that while the pattern of results observed in the more proficient L2 learner group resembled the one observed in English-speaking children (Duncan et al, 2010), the low proficiency L2 group showed a pattern more similar to that of the French speaking children (Quémart et al, 2012). It appears, therefore, that morphemic processing as assessed by our task is sensitive to both language and proficiency.

One advantage of the simple lexical decision task is that it can directly address the issue of how new words are analysed. However, this paradigm is not designed to reveal whether well-known words are automatically decomposed into morphemes, as masked priming studies do. For example, it would be informative to know whether our L2 learners of differing proficiency levels can automatically decompose words into morphemes, and whether or not this corresponds with their pattern of performance in the simple lexical decision task. Future studies are needed to examine the issue of automatic decomposition of complex L2 words according to proficiency level among comparable groups of L2 learners who are carefully matched on L1 and L2 age of acquisition.

It should be noted that some limitations in our study qualify our conclusions. First, we did not include a comparison group of adult monolingual English-speakers, although previous work conducted with English-speaking children with similar materials is helpful in data interpretation. Second, our lexical decision task contained only 15 to 20 stimuli per condition and, although a range of suffixes were investigated, the more productive suffixes (e.g. $<$ er $>$ ) 
were repeated as were the matched non-suffix endings (e.g. $<$ ow $>$ ). This was due to constraints in matching suffix and non-suffix endings in terms of bigram frequency and also reflected the need to ensure that words were sufficiently frequent to be known by low proficiency L2 speakers. Third, while we tested L2 proficiency and familiarity with embedded word forms, we did not assess morphological awareness in L2. Although not usual in adult experiments, this oral test could have provided information about computational aspects of morphological knowledge in the absence of orthographic cues. Such information could help in understanding the contribution of spoken language knowledge versus written language exposure in the development of morphological processing of written words in L2. This is particularly important given our finding that $\mathrm{W}+\mathrm{S}+$ pseudowords are often incorrectly accepted as words. Burani, Marcolini and Giacomo (2002) found a similar result among native -speakers of Italian (adults and children), which was attributed to the semantic interpretability of the pseudowords. This suggests that our late L2 learners, just like the young native-speakers of English in our previous work (Duncan et al, 2010) may be using knowledge of the meaning of both embedded words and suffixes to access the compositional meaning of these $\mathrm{W}+\mathrm{S}+$ pseudoword items. One critical question that relates to the particular L2 context examined here is whether the low proficiency L2 learners are influenced by the considerable overlap between the French and English languages, where suffixes with a similar orthography but not necessarily a similar meaning exist in both languages (e.g. <age>). It will be important to establish whether this orthographic overlap is compensating for the relatively limited orthographic exposure to suffixes in the L2, and whether the meaning that is being accessed by our L2 learners is aligned with the L1 or the L2 version of the suffix.

In conclusion, our contribution joins the debate about morphological processing in L2 in relation to the influence of proficiency. To our knowledge, no previous study has addressed this question by comparing groups of differing proficiency who are matched on both L 2 age of acquisition and L1. Our study provides evidence that words are analysed according to morpheme-like units even by low proficiency L2 speakers. Given that word frequency, bigram frequency and phoneme and letter length were matched between the $\mathrm{W}+$ and $\mathrm{W}$ words, this result strongly implies sensitivity to the morphemic status of the embedded word and that this unit facilitates lexical access in L2. For pseudoword processing, the presence of embedded words and suffixes each led to slower and less accurate classifications. Pseudowords containing the combination of an embedded word and a suffix were frequently incorrectly accepted as words, suggesting that L2 learners are not only sensitive to morphemic components in pseudoword processing but also to their combination. In sum, our study clearly 
shows evidence that L2 learners of low and intermediate to high proficiency make use of written morphemes in recognizing real L2 words and also when they process new words in L2.

References

Baayen, R. H., Dijkstra, T., \& Schreuder, R. (1997). Singulars and plurals in Dutch: Evidence for a parallel dual route model. Journal of Memory and Language, 37, 94-117.

Bertram, R., Baayen, R.H., \& Schreuder, R. (2000). Effects of family size for complex words. Journal of Memory and Language, 42, 390-405.

Burani, C., Marcolini, S., \& Stella, G. (2002). How early does morpholexical reading develop in readers of a shallow orthography? Brain and Language, 81, 568-586.

Carlisle, J. F., \& Stone, C. A. (2005). Exploring the role of morphemes in word reading. Reading Research Quarterly, 40, 428-449.

Clahsen, H., Felser, C., Sato, M. \& Silva, R. (2010). Morphological structure in native and nonnative language processing. Language Learning, 60, 21-43.

Council of Europe E.C. (2001). Common European Framework of Reference for Languages: Learning, Teaching, Assessment. Cambridge University Press.

Deacon, H., \& Whalen, R. (2011). Do children see the danger in dangerous? Grade 4, 6, and 8 children's reading of morphologically complex words. Applied Psycholinguistics, $32(3), 467-481$.

Diependaele, K., Duñabeitia, J. A., Morris, J., \& Keuleers, E. (2011). Fast morphological effects in first and second language word recognition. Journal of Memory and Language, 64, 344-358.

Diependaele, K., Sandra, D., \& Grainger, J. (2005). Masked cross-modal morphological priming: unraveling morpho-orthographic and morpho-semantic influences in early word recognition. Language and Cognitive Processes, 20, 75- 114.

Diependaele, K., Sandra, D., \& Grainger, J. (2009). Semantic transparency and masked morphological priming: The case of prefixed words. Memory \& Cognition, 37, 895908.

Duñabeitia, J.A., Perea, M., \& Carreiras, M. (2008). Does darkness lead to happiness? Masked suffix priming effects. Language and Cognitive Processes, 23, 1002-1020. 
Duncan, L., Casalis, S. \& Colé, P. (2009) Early meta-linguistic awareness of derivational morphology: Some observations from a comparison of English and French. Applied Psycholinguistics, 30, 405-440.

Duncan, L., Gray, E., Quémart, P., \& Casalis, S. (2010). Do good and poor readers make use of morphemic structure in English word recognition? Journal of Portuguese Linguistics, 9/10, 143-160.

Feldman, L. B., Kostic, A., Basnight-Brown, D. M., Filipovic-Durdevic, D., \& Pastizzo M. J. (2009). Morphological facilitation for regular and irregular verb formations in native and non-native speakers: little evidence for two distinct mechanisms. Bilingualism: Language and Cognition, 13, 119-135.

Feldman, L. B., O'Connor, P. A., \& Moscoso del Prado Martín, F. (2009). Early morphological processing is morpho-semantic and not simply morpho-orthographic: A violation of form-then-meaning accounts of word recognition. Psychonomic Bulletin \& Review, 16, 684-691

Gor, K., \& Jackson, S. (2013). Morphological decomposition and lexical access in a native and second language: A nesting doll effect. Language and Cognitive Processes, 28(7), 1065-1091. doi:10.1080/01690965.2013.776696

Kim, S.Y, Wang, M., \& Ko, I.Y. (2011). The processing of derived words in Korean-English bilingual readers. Bilingualism: Language and Cognition 14 (4), 473-488

Lemhöfer, K., Dijkstra, T., Schriefers, H., Baayen, H.R., Grainger, J., \& Zwitserlood, P. (2008). Native language influences on word recognition in a second language: a megastudy. Journal of Experimental Psychology: Learning, Memory, and Cognition, 34, 12-31.

Lemhöfer, K., Koester, D., \& Schreuder, R. (2011). When bicycle pump is harder to read than bicycle bell: Effects of parsing cues in first and second language compound reading. Psychonomic Bulletin \& Review, 18 (2), 364-370.

Longtin, C. M., \& Meunier, F. (2005). Morphological decomposition in early visual word processing. Journal of Memory and Language, 53, 26-41.

Longtin, C. M., Segui, J., \& Hallé, P. A. (2003). Morphological priming without morphological relationship. Language and Cognitive Processes, 18, 313-334.

Marslen-Wilson, W., Tyler, L., Waksler, R., \& Older, L. 1994. Morphology and meaning in the mental lexicon. Psychological Review, 101(1), 3-33.

Masterson, J., Stuart, M., Dixon, M., \& Lovejoy, S. (2003). The Children's Printed Word Database. Retrieved from www.essex.ac.uk/psychology/cpwd. 
Merkx, M., Rastle, K. \& Davis, M. H. (2011). The acquisition of morphological knowledge investigated through artificial language learning. The Quarterly Journal of Experimental Psychology. 64, 6, 1200-1220.

Meunier, F., Longtin, C.-M., (2007) Morphological decomposition and semantic integration in word processing. Journal of Memory and Language, 56, 457-471

New B., Pallier C., Ferrand L., Matos R. (2001) Une base de données lexicales du français contemporain sur internet: LEXIQUE. L'Année Psychologique, 101, 447-462. http://www.lexique.org

Otto, J (2012). Morphological Processing in Bilingual Speakers of German and English. Unpublished $\mathrm{PhD}$ thesis. Royal Holloway, University of London.

Quémart, P, Casalis, S \& Duncan, L (2012). Exploring the role of bases and suffixes when reading familiar and unfamiliar words: evidence from French young readers. Scientific Studies of Reading, 16, 424-442.

Rastle, K., \& Davis, M. H. (2008). Morphological decomposition based on the analysis of orthography. Language and Cognitive Processes, 23, 942-971.

Rastle, K., Davis, M. H., Marslen-Wilson, W. D. \& Tyler, L. K. (2000) . Morphological and semantic effects in visual word recognition: A time-course study. Language and Cognitive Processes. 15, 4-5, 507-537

Rastle, K., Davis, M. H., \& New, B. (2004). The Broth in my brother's brothel: morphoorthographic segmentation in visual word recognition. Psychonomic Bulletin \& Review, 11, 1090-1098.

Schneider, W., Eschmann, A., \& Zuccolotto, A. (Eds.). (2002). E-prime reference guide. Pittsburgh, PA: Psychology Software Tools, Inc.

Schreuder, R., \& Baayen, R. H. (1995). Modeling morphological processing. In L. B.Feldman (Ed.), Morphological aspects of language processing (pp. 131-154). Hillsdale, NJ: Lawrence Erlbaum.

Seidenberg, M.S., \& Gonnerman, L.M. (2000). Explaining derivational morphology as the convergence of codes. Trends in cognitive Sciences, 4, 353-361.

Silva, R., \& Clahsen, H. (2008). Morphologically Complex Words in L1 and L2 Processing: Evidence from Masked Priming Experiments in English. Bilingualism: Language and Cognition, 11, 245-260.

Taft, M. (1994). Interactive-activation as a framework for understanding morphological processing. Language and Cognitive Processes, 9, 271-294. 
Taft, M., \& Forster, K.I. (1975). Lexical storage and retrieval of prefixed words. Journal of Verbal Learning and Verbal Behavior, 14, 638-647.

Ullman, M. (2004). Contributions of memory circuits to language: The declarative/procedural model. Cognition, 92, 231-270.

Ullman, M. (2005). A cognitive neuroscience perspective on second language acquisition: The declarative/procedural model. In C. Sanz (Ed.) Mind and context in adult second language acquisition: Methods, theory and practice (pp. 141-178). Washington, DC: Georgetown University Press. 
Table 1

Participant's characteristics

\begin{tabular}{|c|c|c|}
\hline & Lower Proficiency Group & Higher Proficiency Group \\
\hline Age in Years & $25.00(4.10)$ & $24.12(3.54)$ \\
\hline AoA of English in Years & 8.10 & 8.30 \\
\hline Home environment & Monolingual (100\%) & Monolingual (100\%) \\
\hline \multicolumn{3}{|l|}{ Other languages learned at } \\
\hline \multicolumn{3}{|l|}{ school: number of } \\
\hline \multicolumn{3}{|l|}{ participants } \\
\hline Spanish & 15 (5 years) & 14 (5 years) \\
\hline German & 7 (5 years) & 5 (5 years) \\
\hline Latin & $4(2.6$ years $)$ & $3(1.8$ years $)$ \\
\hline Russian & & 1 (3 years) \\
\hline Self assessment (scale: 1-10) & 5.20 & $8.20 *$ \\
\hline \multicolumn{3}{|l|}{ Times spent abroad in } \\
\hline English Speaking & 0.50 & $13.50 *$ \\
\hline environment (in months) & Range $[0-0.50]$ & Range [4-48] \\
\hline \multicolumn{3}{|l|}{ Vocabulary proficiency } \\
\hline Beginner level (max 50) & $46.80(2.86)$ & $49.00(1.60)$ \\
\hline Intermediate level (max 50) & $17.70(6.60)$ & $38.60(6.40)^{*}$ \\
\hline Advanced level (max 50) & $2.80(4.10)$ & $23.30(9.50)^{*}$ \\
\hline
\end{tabular}

AoA: Age of acquisition.

*: significant differences between groups ( $\mathrm{t}$ test, $\mathrm{p}<.01$ ) 
Table 2

Means (Standard Deviations) for number of letters and of phonemes, frequency (occurrences per million) of words and of Embedded Words as Indicated by the CPWD Database

\begin{tabular}{lllllll}
\hline & \multicolumn{3}{c}{ Words } & & Pseudowords \\
\cline { 2 - 4 } & Number of & Number of & Mean & Embedded & & Embedded \\
& letters & phonemes & word & word & & word \\
& & & frequency & frequency & & frequency \\
W+S + & $6.15(1.09)$ & $5.05(0.69)$ & $62(78)$ & $254(434)$ & & $203(308)$ \\
W+S- & $6.05(0.22)$ & $4.45(0.60)$ & $84(144)$ & $474(1128)$ & \\
W-S+ & $5.95(1.00)$ & $5.05(0.60)$ & $51(60)$ & & \\
W-S- & $5.90(0.55)$ & $4.55(0.94)$ & $45(58)$ & & \\
\hline
\end{tabular}

Note. $\mathrm{W}+\mathrm{S}+$ : presence of an embedded word and a suffix, $\mathrm{W}+\mathrm{S}-$ : presence of an embedded word and absence of suffix, W-S+: absence of embedded word and presence of a suffix, W-Sabsence of embedded word suffix. 
Table 3

Mean percentage accuracy in percentage and mean reaction times for each condition of the lexical decision task (standard deviations in parentheses)

\begin{tabular}{|c|c|c|c|c|}
\hline & $\mathrm{W}+\mathrm{S}+$ & $\mathrm{W}+\mathrm{S}-$ & $\mathrm{W}-\mathrm{S}+$ & W-S- \\
\hline \multicolumn{5}{|l|}{ Words } \\
\hline \multicolumn{5}{|l|}{ Percentage of correct responses } \\
\hline Lower proficiency group & $78.00(13.00)$ & $78.23(9.65)$ & $77.27(10.42)$ & $68.41(13.30)$ \\
\hline Higher proficiency group & $89.47(9.60)$ & $91.69(6.10)$ & $94.04(7.00)$ & $91.05(10.50)$ \\
\hline \multicolumn{5}{|l|}{ Latencies in $\mathrm{ms}$} \\
\hline Lower proficiency group & $724(107)$ & $726(105)$ & $752(107)$ & $754(112)$ \\
\hline Higher proficiency group & 704(90) & $713(106)$ & $700(83)$ & $717(97)$ \\
\hline \multicolumn{5}{|l|}{ Pseudowords } \\
\hline \multicolumn{5}{|c|}{ Percentage of correct responses } \\
\hline Lower proficiency group & $65.23(20.00)$ & $73.64(17.00)$ & $91.39(1.40)$ & $87.05(16.00)$ \\
\hline Higher proficiency group & $81.05(16.00)$ & $88.95(10.00)$ & $96.95(3.60)$ & $96.32(4.40)$ \\
\hline \multicolumn{5}{|l|}{ Latencies in ms } \\
\hline Lower proficiency group & 918(207) & $866(189)$ & $832(176)$ & $824(173)$ \\
\hline Higher proficiency group & $938(214)$ & $840(140)$ & $823(155)$ & $818(161)$ \\
\hline
\end{tabular}

Note. $\mathrm{W}+\mathrm{S}+$ : presence of an embedded word and a suffix, $\mathrm{W}+\mathrm{S}-$ : presence of an embedded word and absence of suffix, W-S+: absence of embedded word and presence of a suffix, W-Sabsence of embedded word suffix. 


\section{Appendix A}

List of words used in the proficiency test

\begin{tabular}{|c|c|c|}
\hline Level 1 & Level 2 & Level 3 \\
\hline Aimer (To love) & Suivre (To follow) & Couler (to run) \\
\hline Voir (To see) & Tuer (To kill) & Le chêne (the oak) \\
\hline Dire (To say) & Le trou (The hole) & Creuser (to hollow) \\
\hline Aller (To go) & Empêcher (To prevent) & Équilibré (balance) \\
\hline La tête (The head) & Gagner (To win) & La voûte (the vault) \\
\hline La nuit (The night) & Partager (To share) & Lâche (loose) \\
\hline La maison (The house) & La maladie (The disease) & Siffler (to whistle) \\
\hline Jeune (Young) & Le toit (The roof) & Boueux (muddy) \\
\hline Travailler (To work) & La colline (The hill) & Envahir (to invade) \\
\hline Vraiment (Really) & La prison (The jail) & Semer (to sow) \\
\hline Le soir (The evening) & L'amitié (Friendship) & La flaque (the puddle) \\
\hline La fille (The girl) & Traverser (To cross) & La jetée (jetty) \\
\hline Donner (To give) & Rêver (To dream) & La gouttière (gutter) \\
\hline Petit (Little) & Le menton (The chin) & L'étincelle (the spark) \\
\hline L'année (The year) & Le tapis (The carpet) & Le poignard (the dagger) \\
\hline L'argent (The money) & Le dessin (The drawing) & Glissant (slippery) \\
\hline Le pays (The country) & Fumer (To smoke) & Le trèfle (trefoil) \\
\hline Parfois (Sometimes) & La chasse (Hunting) & Le pneu (the tyre) \\
\hline Tard (Late) & Le plafond (The ceiling) & Entêté (stubborn) \\
\hline La lumière (The light) & Sauter (To jump) & La boussole (compass) \\
\hline La voiture (The car) & Crier (To shout) & Brancher (to plug in) \\
\hline Devenir (To become) & Le poing (The fist) & Assourdissant (deafening) \\
\hline Parler (To talk) & Le rideau (The curtain) & Hisser (to hoist) \\
\hline Noir (Black) & Le ruisseau (The stream) & Applaudir (to applaud) \\
\hline Croire (To believe) & L'ennui (The boredom) & Ronfler (to snore) \\
\hline \multirow[t]{2}{*}{ Fort (Strong) } & L'écran (The screen) & Élire (to elect) \\
\hline & & La brouette (the \\
\hline Jouer (To play) & La marée (The tide) & wheelbarrow) \\
\hline Lire (To read) & La sagesse (The wisdom) & L'échafaudage (scaffolding) \\
\hline Le ciel (The sky) & La manche (The sleeve) & Ombragé (shady) \\
\hline La fenêtre (The window) & Échouer (To fail) & La prune (the plum) \\
\hline L'ami (The friend) & Plaisanter (To joke) & Les fléchettes (darts) \\
\hline L'église (The church) & Le cerf (The stag) & Le cerf-volant (kite) \\
\hline L'espoir (The hope) & La larme (The tear) & Poignarder (to stab) \\
\hline
\end{tabular}




\begin{tabular}{lll} 
Attendre (To wait) & L'aiguille (The needle) & Espiègle (mischievous) \\
Propre (Clean) & L'outil (the tool) & Patauger (to wade about) \\
Dormir (To sleep) & La casserole (saucepan) & La méduse (jellyfish) \\
La sœur (The sister) & Ranger (to tidy) & Pondre (to lay) \\
Rencontrer (To meet) & La bougie (The candle) & Échiquier (chessboard) \\
L'hiver (The winter) & La chèvre (the goat) & La betterave (beetroot) \\
Acheter (To buy) & L'ongle (the nail) & Éternuer (to sneeze) \\
Oublier (To forget) & L'éventail (the fan) & Tondre (to shear) \\
L'oreille (The ear) & La craie (the shalk) & Bailler (to yawn) \\
Le sable (The sand) & Chuchoter (to whisper) & S'abonner (to suscribe) \\
La tante (The aunt) & Le barrage (the dam) & Chavirer (to capsize) \\
Le doigt (The finger) & Le papillon (the butterfly) & Le pont-levis (drawbridge) \\
Écouter (To listen) & Se raser (to shave) & Surmener (to overwork) \\
Envoyer (To send) & Le phare (the headlight) & Huer (to hoot) \\
Vendre (To sell) & Renverser (to knock over) & Gambader (to gambod) \\
Chanter (To sing) & La mouette (the seagull) & Insonorisé (soundproofed) \\
& Le naufrage (the & \\
Nager (To swim) & shipwreck) & Cambrioler (to burgle) \\
\hline
\end{tabular}




\section{Appendix B}

Detailed list of the Stimuli According to Construction and Lexicality

\begin{tabular}{|c|c|c|c|c|}
\hline & $\mathrm{W}+\mathrm{S}+$ & $\mathrm{W}+\mathrm{S}-$ & W-S+ & W-S- \\
\hline \multicolumn{5}{|l|}{ words } \\
\hline & bony* & barrow & belly** & apple \\
\hline & carriage & bullet & crazy & arrow \\
\hline & cloudy & button & duty & borrow \\
\hline & cookery & castle & easter** & bottle \\
\hline & daily & fellow & finger & elbow \\
\hline & digger & freeze & glitter & follow \\
\hline & dirty & funnel* & hoover & helmet \\
\hline & driver & handle & jealous & kettle* \\
\hline & duster & jacket & leisure & lemon \\
\hline & failure & needle & luggage** & meadow \\
\hline & famous & pillow & marry** & narrow \\
\hline & farmer & rocket & nasty & nugget \\
\hline & gracious & saddle & obvious & quarrel \\
\hline & hopper & settle & pepper** & sneeze \\
\hline & player & shadow & pony & staple \\
\hline & robber & single & pretty & stomach \\
\hline & sadly & spinach & sausage & target \\
\hline & sunny & wallet & sister & travel \\
\hline & teacher & window & spider & turtle \\
\hline & wreckage & yellow & weather & velvet \\
\hline \multicolumn{5}{|c|}{ pseudowords } \\
\hline & cabber & birdet & cusky & birtle \\
\hline & clockage & costle & demmy & bromel \\
\hline & cutous & cupple & dilly** & cottle \\
\hline & farly & cuttle & draly & cunon \\
\hline & hidder & darlow & erdious & forrow \\
\hline & hurriage & dollet & foadous & geavow \\
\hline & hurter & dullow & gopter & gleeze \\
\hline
\end{tabular}




\begin{tabular}{llll}
\hline knower & foodle & hettage & hannow \\
lamper & gappow & hosper & olsow \\
legger & hillet & josy & pirdet \\
lifty & kneeze & moacher & pittle \\
menny & landle & oasher & quabbel \\
nailure & lucket & paiture & segget \\
peacher & missow & raby & spetle \\
platious & notton & reanage & sullow \\
prizer & rollow & sebber & trenach \\
proudy & runnel & slinny & ullow \\
ruly & shamow & stanner & uttle \\
sealy & songle & stiner & volmet \\
weekery & stirach & teeker & walfet \\
\hline
\end{tabular}

Note.

* : words removed from the analysis, being known by less than $50 \%$ of the participants.

** : items removed due to wrong categorisation 